\title{
Do recado da terra aos sinais das estrelas: as lendas e mitos como marcas identitárias em Mia Couto
}

Tatiana Alves Soares Caldas

$\mathrm{CEFET/RJ}$

\begin{abstract}
Resumo
Estórias Abensonhadas, livro de contos publicado em 1994, é marcado pela recuperação de valores e por um traço característico de praticamente todos os contos que o integram, e que se faz presente em muitas narrativas do período pós-colonial: a perspectiva do sonho em meio à violência e à guerra. Por meio de histórias que remetem a mitos e lendas do imaginário africano, ocorre o resgate de traços soterrados por um passado colonial e por guerras civis. $\mathrm{O}$ emergir da ancestralidade e das tradições locais surge como algo fundamental à construção de uma identidade moçambicana, numa proposta que se faz a partir dos valores da terra. Os contos que integram a obra traduzem a perspectiva do sonho em uma terra que aos poucos se reconstrói. Vendo em tais narrativas uma tentativa simultânea de resistência aos valores pragmáticos impostos pelo colonizador e de resgate de uma identidade calcada na oralidade e nos mitos de origem, nosso estudo busca analisar tais manifestações nos referidos contos como mecanismos de afirmação e de reconstrução de uma identidade nacional.
\end{abstract}

Palavras-chave: Mia Couto; Ancestralidade; Mitos; Memória; Resistência.

\begin{abstract}
Estórias Abensonhadas, book of short stories published in 1994, is marked by the recovery of values and a characteristic feature of almost every tale it comprises, and that is present in many narratives of the post-colonial period: the dream perspective amid violence and war. Through stories that refer to myths and legends of the African imaginary, there is the rescue of buried traces of a colonial past and by civil wars. The emergence of ancestry and local traditions emerges as something fundamental to the construction of a Mozambican identity, a proposal that is made from earth values. The stories that make up the work present the dream prospect in a land that gradually rebuilds. Seeing in these narratives a simultaneous attempt to resist the pragmatic imposed by the colonizer values and redemption of a grounded identity in oral and origin myths, our study seeks to analyze such events in these tales as an affirmation mechanism of rebuilding a national identity.
\end{abstract}

Keywords: Mia Couto; Ancestry; Myths; Memory; Resistance. 
1. VENÂNCIO, José Carlos.

Literatura e poder na África lusífona, 1992, p. 62.
Estórias Abensonhadas, livro de contos publicado em 1994, é marcado pela recuperação de valores e por um traço característico de praticamente todos os contos que o integram, e que se faz presente em muitas narrativas do período pós-colonial: a perspectiva do sonho. Por meio de histórias que se inscrevem no território do maravilhoso, ocorre o resgate de traços soterrados por um passado colonial e por guerras civis. $\mathrm{O}$ emergir da ancestralidade e das tradições locais surge como algo fundamental à construção de uma identidade moçambicana, em uma proposta que se faz a partir dos valores da terra.

Circunstâncias históricas - algumas das quais significativamente marcadas pelo viés do maravilhoso - prenunciam a chegada de um novo tempo, de sonho e de reconstrução. Em Moçambique, teria havido uma chuva, surgida após um longo período de seca, coincidindo com o fim da guerra e assinalando, em termos simbólicos, o nascer de um novo tempo. $\mathrm{O}$ vislumbre do sonho propiciado por esse novo período é analisado por Mia Couto, ao explicar o contexto de surgimento de Estórias Abensonhadas. Ao pensar a gênese da obra, o autor relaciona o retorno da chuva à perspectiva de reconstrução do país:

Há esse enorme desafio no meu país de que a terra se reconcilie consigo própria, e eu escrevi um livro que se chama Estórias Abensonhadas. Esse termo abensonhadas surgiu no dia em que Moçambique, depois desse tempo amargo de guerra, conquistou a paz. Foi assinado o acordo de paz, e eu pensava que ia encontrar as pessoas festejando na rua, porque havia uma imensa alegria escondida por trás daquele acontecimento oficial. Mas ninguém saiu para a rua. Uma semana depois, sim, as pessoas saíram para a rua porque choveu. Então, eu vi que a mesma razão que ditava a guerra, que eram os antepassados, os deuses antepassados, estavam zangados com os homens, esses mesmos deuses tinham aprisionado as chuvas. E o fato de eles terem liberado a chuva, agora significava que sim, que era verdade a notícia de paz; vinha não pelo rádio, não pelo jornal, mas pela própria chuva. Daí a chuva ser tida como abençoada, como sonhada, como abensonhada. ${ }^{1}$

O neologismo, marca de sua escrita, acaba por traduzir, no âmbito literário, o desejo de libertação e de renovação presentes no período. A própria aglutinação de abençoadas e sonhadas, ambas pertencentes a um campo semântico positivo, reflete o otimismo como a tônica de Estórias Abensonhadas, conferindo um teor sagrado ao sonho de Paz. Sobre o neologismo como indicativo de uma liberdade política, o próprio Mia Couto estabelece tal relação, ao pensar o seu processo de criação:

Tenho conseguido reascender da infância usando uma língua que também está em estado de infância, que não está acabada. Quando consigo isso, passo a ter um pensamento 
mais criativo, passo a ter uma relação com o mundo. Como se o mundo ainda estivesse em fabricação e eu pudesse brincar com ele. ${ }^{2}$

Além do aspecto demiúrgico contido na criação lexical, o neologismo acaba por servir a outro propósito: sendo o autor, segundo suas próprias palavras, um ser de fronteira - branco, filho de portugueses, e um escritor que se utiliza da Língua Portuguesa, originalmente a língua do colonizador -, o recurso aos neologismos demarca, linguisticamente, um movimento de apropriação em relação ao idioma do opressor. A respeito da visão de si mesmo como ser de fronteira, tal definição é explicitada por ele em entrevistas, momentos em que ele reflete acerca da escrita e do hibridismo de sua condição.

O reconhecimento dessa condição híbrida, em que a nacionalidade moçambicana traz consigo a ascendência europeia, faz de Couto um escritor cuja vivência é marcada por um olhar a um só tempo interno e externo em relação a Moçambique. Os neologismos, indicativos do anseio por liberdade, traduzem ainda uma atitude de transgressão em relação à língua do colonizador, o que confere a seu uso uma feição ideológica ainda mais definida. Em Mia Couto: espaços ficcionais, Maria Nazareth Fonseca e Maria Zilda Cury destacam tal faceta na obra do escritor moçambicano:

A tematização da escrita [...] está sempre presente na ficção de Mia Couto: metalinguisticamente encenando o ato de escrever e de ler, simbolizando o mundo do colonizador, apropriada a seu modo pelo colonizado, distendendo, alargando os espaços da própria literatura, inscrevendo-se na terra, na água, no fogo. ${ }^{3}$

"Nas águas do tempo", conto que abre o livro, narra a história de um menino que é constantemente levado pelo avô a um rio que deságua em um lago. $\mathrm{O}$ avô cumprimenta seres que o menino não consegue ver. No instante em que o avô morre, o menino finalmente consegue enxergar os panos brancos na outra margem, bem a tempo de reconhecer o lenço vermelho do avô, que, nesse momento, também se torna branco, indicando que ele agora pertence ao grupo da outra margem. Ao final da história, é o menino, já adulto, quem aparece conduzindo o filho, sabendo-se responsável pela transmissão e pela perpetuação dos segredos de seu grupo social, e sugerindo a permanência da tradição legada pelo avô.

O final do texto é marcado pela certeza de que as crenças serão passadas adiante, pois é o menino, já adulto, quem hoje conduz o filho, para que este lhe siga, um dia, os passos:

Enquanto remava um demorado regresso, me vinham à lembrança as velhas palavras de meu velho avô: a água e o
2. Entrevista ao Jornal Mil

Folhas, publicada em 28/9/2002.

3. FONSECA, Maria Nazareth Soares \& CURY, Maria Zilda

Ferreira. Mia Couto: espaços

ficcionais, 2008, p. 36. 
4. COUTO, Mia. Estórias abensonhadas, 2008, p. 17.

5. Ibidem, p. 59.

6. Ibidem, p. 59.

7. Ibidem, p. 60. tempo são irmãos gémeos, nascidos do mesmo ventre. E eu acabava de descobrir em mim um rio que não haveria nunca de morrer. A esse rio volto agora a conduzir meu filho, lhe ensinando a vislumbrar os brancos panos da outra margem. ${ }^{4}$

"Vislumbrar os panos" significa aprender a ancestral lição sobre vida e morte, e a atitude do narrador revela a sua decisão de passar adiante os valores de seus antepassados.

"Chuva: a abensonhada" é talvez o conto que mais se aproxima do eixo norteador da obra: a mensagem de esperança trazida simbolicamente pela chuva torrencial que caiu sobre Moçambique dias após a assinatura do Acordo de Paz. É ela que abençoa a paz tão sonhada, em um sinal de que agora, sim, os deuses estavam de fato satisfeitos.

A mensagem de recomeço fica patente nas palavras iniciais, quando o narrador, mirando a chuva que insiste em cair, reflete acerca da perspectiva de esperança por ela simbolizada:

Estou sentado junto da janela olhando a chuva que cai há três dias. Que saudade me fazia o molhado tintintinar do chuvisco. A terra perfumegante semelha a mulher em véspera de carícia. Há quantos anos não chovia assim? De tanto durar, a seca foi emudecendo a nossa miséria. O céu olhava o sucessivo falecimento da terra e, em espelho, se via morrer. A gente se indaguava: será que ainda podemos recomeçar, será que a alegria ainda tem cabimento ${ }^{5}$

Os neologismos utilizados pelo narrador reiteram a imagem de renovação representada pela chuva: perfumegante, fundindo as noções do calor da terra, fumegante, e do exalar de um perfume inconfundível de liberdade, ou indaguava, sugerindo as indagações trazidas pela chuva que desaguava no país.

O local onde o narrador se encontra atua como metonímia da nação moçambicana, como se percebe em suas palavras: "Estou espreitando a rua como se estivesse à janela do meu inteiro país"6.

Tristereza, a tia que lê os recados da terra, percebe que a chuva assinala um novo momento na história do país, marcado pela redenção e pela bênção dada pelos ancestrais:

[...] A idosa senhora não tem dúvida: a chuva está a acontecer devido das rezas, cerimónias oferecidas aos antepassados. Em todo o Moçambique a guerra está a parar. Sim, agora já as chuvas podem recomeçar. Todos estes anos, os deuses nos castigaram com a seca. Os mortos, mesmo os mais veteranos, já se ressequiam lá nas profundezas. ${ }^{7}$

Outro aspecto relevante refere-se ao contraste estabelecido entre o saber científico, cartesiano, racional, representado pela 
figura do narrador, e a leitura da terra, dos elementos, na visão intuitiva e telúrica simbolizada por Tristereza. Esta, conhecedora de tempos e temperos, mostra ao sobrinho visões que não cabem no raciocínio pragmático deste:

- Mas, Tia Tristereza: não será está chover de mais?

- De mais? Não, a chuva não esqueceu os modos de tombar, diz a velha. [...]

Tristereza olha a encharcada paisagem e me mostra outros entendimentos meteorológicos que minha sabedoria não pode tocar.

[...]

- Lá em cima, senhor, há peixes e caranguejos. Sim, bichos que sempre acompanham a água.

$[\ldots]$

- Sim, finjo acreditar. E quais tipos de peixes?

Negativo: tais peixes não podem receber nenhum nome. Seriam precisas sagradas palavras e essas não cabem em nossas humanas vozes. ${ }^{8}$

O diálogo entre o narrador e a tia retrata o choque entre a tradição e o novo. Tristereza representa um passado de tristeza, sugerido inclusive por seu nome, aglutinação de triste e de Tereza, mas, por outro lado, configura-se como detentora de um conhecimento intuitivo, de uma sabedoria da terra. Já o sobrinho, racional, se apresenta como alguém que inicialmente questiona a validade do conhecimento da tia para, ao final, reconhecer-lhe o valor:

- A chuva está a limpar a areia. Os falecidos vão ficar satisfeitos. Agora, era bom respeito o senhor usar este fato. Para condizer com a festa de Moçambique...

[...] [Tristereza] acredita que acabou o tempo de sofrer, nossa terra se está lavando do passado. ${ }^{9}$

A chuva molha as sementes que irão brotar, em uma simbólica imagem de reconstrução do país. E, em um sinal de que o futuro será reconstruído a partir do equilíbrio entre tradição e renovação, o narrador cede ao pedido da tia, vestindo a roupa que ela julga adequada à ocasião:

- Tristereza, tira o meu casaco.

Ela se ilumina de espanto. Enquanto despe o cabide, a chuva vai parando. Apenas uns restantes pingos vão tombando sobre o meu casaco. Tristereza me pede: não sacuda, essa aguinha dá sorte. E, de braço dado, saímos os dois pisando charcos, em descuido de meninos que sabem do mundo a alegria de um infinito brinquedo. ${ }^{10}$

O final da narrativa conduz a uma mensagem de esperança: abençoados pela chuva, Tristereza e o sobrinho são agora livres para usufruir o mundo como se de um brinquedo se tratasse.
8. Ibidem, p. 61.

9. Ibidem, p. 61.

10. Ibidem, p. 62. 
11. Ibidem, p. 29-30.

12. Ibidem, p. 31.
Ambos, de braços dados, em uma união de mundos, memórias e saberes, aliam-se para celebrar o renascer de seu país.

Em "O cego Estrelinho", tem-se uma narrativa que contrapõe o mundo real, da guerra, a um mundo sonhado, onde tudo é belo. Tal oposição é feita mediante o contraste entre o mundo real, desconhecido pelo cego que dá título ao conto, e o mundo retratado a ele pelo guia, Gigito. Este conduz Estrelinho a um lugar de fantasia e beleza, e é por meio de seus olhos que o cego trava contato com o mundo. Privado da visão do mundo real, o cego tem acesso a um mundo imaginado, permeado de encantamento:

Gigitinho, porém, o que descrevia era o que não havia. O mundo que ele minuciava eram fantasias e rendilhados. A imaginação do guia era mais profícua que a papaeira.

[...] A mão do guia era, afinal, o manuscrito da mentira. Gigito Efraim estava como nunca esteve São Tomé: via para não crer. [...] Desfolhava o universo, aberto em folhas. A ideação dele era tal que mesmo o cego, por vezes, acreditava ver. ${ }^{11}$

Em uma perversa ironia, a guerra tira o guia ao cego, que se vê desprovido de sua capacidade de enxergar, ainda que indiretamente, o mundo. Note-se, quando da ausência do guia, a sensação de desamparo vivenciada pelo cego:

Mas a resposta de Gigito não veio, num silêncio que foi seguindo, esse sim, repetido e igual. Desamimado, Estrelinho ficou presenciando inimagens, seus olhos no centro de manchas e ínvias lácteas. Aquela era uma desluada noite, tinturosa de enorme. Pitosgando, o cego captava o escuro em vagas, despedaços. O mundo lhe magoava a desemparelhada mão. ${ }^{12}$

Interessantes são os neologismos utilizados para retratar a nova condição do cego: inimagens, invias lácteas e desluada sugerem não somente a ausência, mas a destituição - acentuada pelos prefixos de negação - de algo que um dia existiu, ainda que apenas no sonho. A perda de Gigito equivale, para Estrelinho, a uma segunda cegueira.

Surge, então, Infelizmina, irmã de Gigito, que vem tomar o lugar do irmão na tarefa de cuidar de Estrelinho. Seu olhar para o mundo, contudo, não possui a perspectiva sonhadora com que o antigo guia o retratava ao cego. Assim, Estrelinho é lançado à desilusão, em um mundo destituído de esperança:

Desde então, a menina passou a conduzir o cego. Fazia-o com discrição e silêncios. E era como se Estrelinho, por segunda vez, perdesse a visão. Porque a miúda não tinha nenhuma sabedoria de inventar. Ela descrevia os tintins da 
paisagem, com senso e realidade. Aquele mundo a que o cego se habituara agora se desiluminava. Estrelinho perdia os brilhos da fantasia. ${ }^{13}$

Entretanto, em uma reviravolta na trama, Infelizmina e Estrelinho apaixonam-se e, logo em seguida, são informados da morte de Gigito na guerra, fato que desencadeia um processo depressivo na moça, que começa paulatinamente a definhar. Estrelinho, então, começa a descrever o seu mundo, repleto de sonho, invertendo a perspectiva: pelo amor e pela esperança, é ele quem agora a conduz. Ela, de guia referencial, passa a ser guiada por ele, enxergando um mundo que nunca veria com os próprios olhos. A moça, que já trazia a infelicidade no nome, é agora impregnada pela magia do mundo que se descortina aos seus olhos. Se Estrelinho carecia de um guia no mundo real, é ele o guia nessa nova jornada, capaz de se transmutar aos olhos de quem nela acredita. Subvertendo o conhecido ver para crer, Estrelinho consegue fazer com que a moça creia para, dessa forma, ver.

[...] Até que a ela se chegou o cego e lhe conduziu para a varanda da casa. Então, iniciou de descrever o mundo, indo além dos vários formamentos. Aos poucos foi despontando um sorriso: a menina se sarava da alma. Estrelinho miraginava terras e territórios. Sim, a moça, se concordava. Tinha sido em tais paisagens que ela dormira antes de ter nascido. ${ }^{14}$

A visão de Estrelinho, fusão de miragens e de uma imaginação que o habilita a ler o mundo de outra forma - ele miraginava - traduz a perspectiva de reconstrução, por parte de alguém capaz de converter em realidade aquilo que acredita ser real. Ao enxergar um mundo diferente do verdadeiro devido à sua deficiência visual, é capaz de criar um mundo de sonho e de fazer com que outros assim o vejam, em uma mensagem de esperança. O final, pleno de otimismo, vem nas palavras do próprio Estrelinho, que se dispõe a mostrar o caminho para o lindo mundo por ele apresentado.

Em As flores de Novidade, é contada a história de Novidade Castigo, menina diferente, que, segundo o texto, parece ter vindo ao mundo como punição, pois é vista com desconfiança pelo fato de ser filha de negros e possuir olhos azuis. Enquanto todos vivenciam a realidade, ela passa o tempo cantando e recolhendo pétalas azuis, de origem desconhecida. É marcada pela beleza e pela alegria, em contraste com uma realidade em que a guerra se faz cada vez mais presente. Depois de um episódio em que a moça é acometida por convulsões, a guerra chega ao lugar e todos têm de ser retirados dali. Novidade, ao contrário dos demais, não parece querer ir embora e, alheia a tudo, põe-se a colher flores silvestres. O caminhão em que todos partem segue
13. Ibidem, p. 32.

14. Ibidem, p. 33. 
15. Ibidem, p. 35.

16. Ibidem, p. 68. sem ela, e a mãe, contudo, consegue ainda ver de longe a moça sendo tragada por flores que a puxam para dentro da terra:

O que se passou, quem sabe, só ela viu. Lá, entre a poeira, o que sucedia era as flores, aquelas de olhar azul, se encherem de tamanho. E, num somado gesto, colherem a menina. Pegaram Novidadinha por suas pétalas e a puxaram terra-abaixo. A moça parecia esperar esse gesto. Pois ela, sempre sorrindo, se susplantou, afundada no mesmo ventre em que via seu pai se extinguir, para além das vistas, para além do tempo. ${ }^{15}$

Ao apresentar Novidade sendo tragada por flores de olhar azul, semelhantes ao seu, que a libertam das atrocidades da guerra, o texto traz a mensagem de que nas raízes da terra residiria a esperança. Seria por meio de um mergulho nas entranhas do solo de seu país que o homem encontraria a esperança de um mundo livre de guerras.

Semelhante imagem pode ser vista em "O cachimbo de Felizbento", em que o desaparecimento do protagonista representa um retorno às raízes, ao âmago da terra. Quando a guerra surge, rápida e avassaladora, Felizbento decide só ir embora se puder levar as árvores do lugar consigo. Diante da inviabilidade de seu projeto, ele mergulha na terra e desaparece. A fumaça de seu cachimbo, entretanto, reaparece periodicamente, indicando que ele aguarda, no seio da terra, o momento de regressar:

Os que voltaram ao lugar dizem que, sob a árvore sagrada, cresce agora uma planta fervorosa de verde, trepando em invisível suporte. E asseguram que tal arvorezinha pegou de estaca, brotando de um qualquer cachimbo remoto e esquecido. E, na hora dos poentes, quando as sombras já não se esforçam, a pequena árvore esfumaça, igual uma chaminé. Para a esposa, não existe dúvida: em baixo de Moçambique, Felizbento vai fumando em paz o seu velho cachimbo. Enquanto espera a maiúscula e definitiva Paz. ${ }^{16}$

Além de o texto mostrar uma imagem singela da morte do personagem, esta surge como forma de apropriação da terra, em uma atitude que traduz, em tempos de guerra, a retomada do país por seus filhos. Felizbento é duplamente marcado, pois é felize abençoado, sendo aquele que aguarda o tempo de paz para Moçambique.

Mesmo nos contos em que a mensagem de esperança não é tão explícita, há no final uma semente que aponta, talvez no futuro, uma saída. Em "O poente da bandeira", talvez um dos mais realistas e crus relatos sobre a guerra dentre os que compõem o livro, há a figura de um menino que, em uma espécie de ritual, pede para ser cortado para poder sonhar: 
Para sonhar o menino tinha que sangrar. A avó lhe cedia o jeito, habituada à lâmina como outras mães se acostumam ao pente. $\mathrm{O}$ sangue espontava e o mundo presenciava o futuro, tivesse a barriga prenhe do tempo encostada em seu ouvido. ${ }^{17}$

Além de apresentar a metáfora de que o verdadeiro sonho exige a dor, ou seja, para se ver o sonho, há que se sangrar, o conto mostra a crueldade da guerra em sua face mais odiosa: o menino acaba sendo morto com truculência por um soldado, por não saber como se comportar em uma determinada situação. E, se a bandeira constitui-se em metonímia da nação, é expressivo o fato de suas cores parecerem se esmaecer quando da morte da criança:

Sente o sangue escorrendo, a bota do soldado ainda lhe dói uma última vez. Como pode saber ele os procedimentos exigidos pelo vigilante? Mas o soldado é totalmente militar, está só cumprindo ignorâncias, jurista de chumbo incapaz de distinguir um fora-da-lei de um da lei-de-fora. [...] À medida que o soldado desfere mais violência, a bandeira parece perder as cores, a paisagem em redor esfria e a luz tomba de joelhos. É, então. ${ }^{18}$

O jogo de palavras feito a partir das expressões fora-da-lei $\mathrm{e}$ da-lei-de-fora denuncia as atrocidades cometidas por quem detém o poder, tratando como criminosos aqueles que não se adaptam ao código arbitrário que lhes é imposto.

$\mathrm{E}$, sob o viés do maravilhoso, eis que uma árvore tomba sobre o soldado, como que a vingar a morte do inocente. A árvore, símbolo da terra, reage à morte da criança e, ainda que haja versões tentando encontrar uma explicação racional para o ocorrido, todos sabem que a terra vingou o assassinato de um de seus filhos:

A árvore estava já morta, ainda houve o dito. Poucos criam. A crença estava com a avó, sua outra versão: o tronco se desmanchara, líquido, devido à morte daquela criança. Vingança contra as injustiças praticadas contra a vida. [...] A palmeira sumiu mas para sempre ficara a sua ausência. Quem passe por aquele lugar escuta ainda o murmúrio das suas folhagens. A palmeira que não está conforta a sombra de um menino, sombra que persiste no sol de qualquer hora. ${ }^{19}$

Em uma espécie de mito, à semelhança do que ocorre em outros contos do livro, o final sugere que o murmúrio e a sombra da palmeira permanecem, não importando o sol, e que sempre continuará a proteger os meninos de sua terra, reiterando a integração homem/terra que perpassa a obra.
17. Ibidem, p. 71.

18. Ibidem, p. 72-73.

19. Ibidem, p. 73. 
20. HALL, Stuart. Da Diáspora

- Identidades e Mediações Culturais, 2006, p. 61.

21. SECCO, Carmen Lucia Tindó Ribeiro. "O ar, as águas e os sonhos no universo poético de Mia Couto”, 1998, p. 161.
Estórias abensonhadas reflete um momento de redefinição da identidade nacional. Stuart Hall, em $A$ identidade cultural e diáspora, afirma a necessidade de o homem se inscrever na sociedade, seja por meio de um resgate do passado, seja por sua inserção no futuro, em um processo em que a construção identitária se faz por meio de uma relação cultural com o tempo e com a história:

As identidades culturais provêm de alguma parte, têm histórias. Mas, como tudo o que é histórico, sofre transformações constantes. Longe de fixas eternamente em algum passado essencializado, estão sujeitas ao contínuo "jogo" da história, da cultura e do poder. As identidades, longe de estarem alicerçadas numa simples "recuperação" do passado, esperam para ser descobertas e que, quando o for, há de garantir a percepção de nós mesmos na eternidade, são apenas os nomes que aplicamos às diferentes maneiras que nos posicionam, e pelas quais nos posicionamos, nas narrativas do passado. $^{20}$

A preocupação no sentido de não permitir que o passado se perca assume, na narrativa de Mia Couto, contornos ideológicos bem definidos, traduzindo uma postura de resistência frente aos valores impostos pelo colonizador.

Nesse sentido, a ficção surge como perspectiva da reconstrução vislumbrada pela escrita pós-colonial. Assiste-se, pelo novo texto que se impregna da memória coletiva, à reconstrução de um país pelo viés da memória ancestral, soterrada pela visão colonialista:

Mitos, ritos e sonhos são caminhos ficcionais trilhados pelas narrativas de Mia Couto que enveredam pelos labirintos e ruínas da memória coletiva moçambicana como uma forma encontrada para resistir à morte das tradições causada pelas destruições advindas da guerra. As úlceras deixadas nas paisagens são deploradas pela escritura mitopoética do autor, cujo lirismo funciona como bálsamo cicatrizante e cuja lucidez política serve para abrir os olhos do povo, numa tentativa de curar a cegueira reinante em Moçambique, nos atuais tempos pós-coloniais. ${ }^{21}$

Estórias abensonbadas obedece a um movimento duplo, em que se alternam e se complementam duros retratos da guerra e possibilidades de saída pelo sonho. O maravilhoso surge por vezes como negação dessa crueza e acena com a perspectiva da reconstrução. Na literatura do momento pós-colonial, assiste-se ao emergir das vozes que por tanto tempo foram silenciadas e, nesse processo de reconstrução, a escrita de Mia Couto surge como mais um traço desse país que aos poucos se redescobre, pleno e abensonhado. 


\section{Referências}

BOSI, Ecléa. Memória e sociedade: lembranças de velhos. São Paulo: Companhia das Letras, 2003.

CHEVALIER, Jean \& GHEERBRANT, Alain. Dicionário de símbolos. Rio de Janeiro: José Olympio, 1990.

COUTO, Mia. Estórias abensonhadas. Lisboa: Editorial Caminho, 2008.

FONSECA, Maria Nazareth Soares \& CURY, Maria Zilda Ferreira. Mia Couto: espaços ficcionais. Belo Horizonte: Autêntica Editora, 2008.

HALL, Stuart. Da Diáspora - Identidades e Mediações Culturais. Belo Horizonte: Editora UFMG, 2006.

SECCO, Carmen Lucia Tindó Ribeiro. "O ar, as águas e os sonhos no universo poético de Mia Couto”. Gragoatá. n5. Niterói: UFF, 1998.

VENÂNCIO, José Carlos. Literatura e poder na África lusófona. Lisboa: Instituto de Cultura e Língua Portuguesa, 1992. 
